\title{
Happiness is not Well-Being
}

\author{
Jason R. Raibley
}

(C) Springer Science+Business Media B.V. 2011

\begin{abstract}
This paper attempts to explain the conceptual connections between happiness and well-being. It first distinguishes episodic happiness from happiness in the personal attribute sense. It then evaluates two recent proposals about the connection between happiness and well-being: (1) the idea that episodic happiness and well-being both have the same fundamental determinants, so that a person is well-off to a particular degree in virtue of the fact that they are happy to that degree, and (2) the idea that happiness in the personal attribute sense can serve as a "proxy" for well-being, i.e., that a person's degree of deep or robust happiness approximates their degree of well-being. It is argued that happiness in both these senses is conceptually, metaphysically, and empirically distinct from wellbeing. A new analysis of welfare, well-being as agential flourishing, can explain welfare's real connection to happiness in both the episodic and personal attribute senses. It predicts that such happiness is only directly beneficial when it is valued, when it is a form of valuing, or when it underwrites (i.e., serves as the causal basis for) the disposition to realize one's values. It is therefore a necessary—but not sufficient—condition for especially high levels of well-being. This analysis of welfare integrates many insights from the eudaimonic tradition of welfare and happiness research in psychology, and also addresses common criticisms of these eudaimonic models.
\end{abstract}

Keywords Happiness · Well-being · Welfare · Fred Feldman · Daniel Haybron · Agential flourishing $\cdot$ Eudaimonia $\cdot$ Eudaimonism

\section{Introduction}

In The Principles of Morals and Legislation, Jeremy Bentham writes:

By utility is meant that property in any object, whereby it tends to produce benefit, advantage, pleasure, good, or happiness, (all this in the present case comes to the

J. R. Raibley $(\bowtie)$

Department of Philosophy, California State University, 1250 Bellflower Blvd,

Long Beach, CA 90840, USA

e-mail: jraibley@csulb.edu 
same thing) or (what comes again to the same thing) to prevent the happening of mischief, pain, evil, or unhappiness to the party whose interest is considered ... (Bentham, 1907 §1.2-3).

Here, Bentham indicates that benefit, advantage, good, happiness, and pleasure all "come ... to the same thing." Those who reject hedonism about well-being will of course have reason to challenge his claim that pleasure comes to the same thing as benefit or advantage. But what about the other connection Bentham proposes? As the term "happiness" is now used, is it true that happiness and personal benefit or advantage-i.e., wellbeing or welfare ${ }^{1}$ - come to the same thing? Some contemporary social scientists seem to think so. For example, Richard Easterlin writes that "the terms well-being, utility, happiness, life satisfaction, and welfare [are] interchangeable ..." (2005, p. 29). Is this correct, or does ordinary English usage mark a theoretically important difference between happiness and well-being? More generally, what is the connection between these two phenomena?

This paper attempts to answer these questions. Section 2 makes some conceptual clarifications necessary for this project, first distinguishing episodic happiness from happiness in the personal attribute sense. It then shows how ordinary English usage distinguishes between both these forms of happiness (on the one hand) and well-being (on the other). Section 3 evaluates two recent proposals about the connection between happiness and well-being. It first argues against the idea that episodic happiness and well-being both have the same fundamental determinants, so that a person is well-off to a particular degree in virtue of the fact that they are happy to that degree. It then argues against the claim that happiness in the personal attribute sense can serve as a "proxy" for well-being, i.e., that a person's degree of deep or robust happiness approximates their degree of well-being. Happiness in both these senses is therefore conceptually, metaphysically, and empirically distinct from well-being.

Section 4 then presents a model of well-being that explains its connection to happiness in both the episodic and personal attribute senses. According to this model, well-being as agential flourishing, an adult human person is doing well at a time to the degree that they resemble the paradigm case of the flourishing agent at that time. The paradigm case of the flourishing agent is a person who successfully realizes their values and is stably disposed to do so. This theory allows that both forms of happiness are important determinants of wellbeing, and that they are necessary-but not sufficient—conditions for enjoying especially high levels of well-being.

This theory makes several important empirical assumptions about which states and conditions in fact support or underwrite the disposition to realize one's values. These assumptions need testing and confirmation by psychologists, if the theory's explanatory power is to be fully vindicated. However, the theory seems viable on account of its congruence with common-sense thinking about who is doing well, who is not, what conditions would benefit (or harm) given individuals, and the normative importance of welfare.

It should be emphasized that the theory is not designed to accord with the explicit theories of welfare held by ordinary people. Such theories may diverge from the use of the

\footnotetext{
1 Here, the terms "well-being" and "welfare" are used as synonyms, as is common practice in philosophy (see, e.g., Sumner 1996). Both these terms are taken to express the concept of prudential good, i.e., one's own interests, i.e., personal advantage. This concept is described in more detail at the end of Sect. 2. Philosophical practice, here, differs from practice among those social scientists who use "welfare" as a synonym for "utility," where this latter is understood as revealed preference-satisfaction (Von Neumann and Morgenstern 1944; Binmore 2009).
} 
welfare vocabulary by ordinary people, which is a better guide to the meaning of the relevant terms (Wittgenstein 1958; Putnam 1975). However, the theory is designed to predict and explain particular, common-sense judgments that ordinary people make about who is faring well and who is faring badly. It is also designed to comport with ordinary thinking about the normative force of considerations of welfare, so that it makes sense for people to care about well-being to the degree that they obviously do. This ensures that the model is actually a model of well-being and not of some other phenomenon in the vicinity. If the model is successful in both these respects, then it avoids problems with the wellknown subjective well-being (SWB) model. Interpreted as a theory of welfare, this view holds that well-being consists in life-satisfaction, the presence of positive mood, and the absence of negative mood (see, e.g., Diener 2000). As others have noted, this model neither fits with ordinary intuitions about benefit and harm nor vindicates well-being's normative important (Tiberius and Hall 2010; Seligman 2011).

There is further evidence in favor of well-being as agential flourishing in its ability to incorporate insights from psychology's eudaimonic tradition of welfare and happiness research (Ryan and Deci 2001; Della Fave 2011b). Section 5 explains how the theory acknowledges the bearing on personal well-being of activities, processes, and states highlighted by leading eudaimonic models. Such models include, especially, Ryan and Deci's self-determination theory (1995), the theories of mental health and positive psychological functioning defended by Ryff and Keyes (1995), and the theory of personal expressiveness proposed by Waterman (1993). In particular, the agential flourishing model concurs that the pursuit and achievement of valued goals, mental health or psychological functioning, and activities that are congruent with deeply held values are central, nonhedonic determinants of well-being.

Furthermore, as is also explained in Sect. 5, the theory can address two common criticisms of the eudaimonic tradition. First, some psychologists criticize eudaimonic models on account of the lack of convergence among contemporary eudaimonic theorists (Biswas-Diener et al. 2009). If well-being as agential flourishing is true, then this is a less serious of problem than it initially seems, because leading eudaimonic models can be seen as illuminating complementary aspects of a single phenomenon. Second, some psychologists argue against eudaimonic models and in favor of SWB (at least as the most trustworthy symptom of welfare) because they believe that eudaimonic models are elitist or paternalistic and impose values on others (e.g., Kashdan et al. 2008). By focusing on an individual's actual values regardless of their content (as well as all the capacities, resources, and systems that make the realization of these values possible), well-being as agential flourishing also addresses this criticism.

None of this is to denigrate the SWB model, which has made possible numerous important empirical discoveries (Kahneman et al. 1999). But if the theory presented here is correct, then measures of SWB-particularly its affective components-very likely measure episodic happiness. This is a perfectly real and important phenomenon, and indeed one that regulates much of our ordinary talk about happiness. However, it is only one determinant of well-being.

\section{Conceptual Preliminaries}

Any investigation into the relation between happiness and well-being is complicated by the fact that there is considerable controversy about both (a) which property is expressed by the predicate "is happy," and (b) the proper analysis of this property, i.e., the correct 
explanation of its ultimate nature. Furthermore, there is controversy about (c) the correct analysis of the property of well-being. This section further explains each of these controversies and the bearing that they have on the current project and its argumentative strategy.

\subsection{Properties Called Happiness}

There are two main proposals in the philosophical literature concerning which property is conventionally expressed by the ordinary English predicate, "is happy." These are different proposals, not about the deep nature of happiness, but about what property we are exchanging information about when we use the predicate, "is happy."

First, many contemporary philosophers hold that this predicate expresses a psychological property: the property of feeling happy at a time, or episodic happiness (Feldman 2010 , pp. 127-136). This property is sometimes also called "the feeling of happiness," "momentary happiness," or "the occurrent sense of happiness," or-in the psychological literature-"hedonia." There are then a variety of theories about the deep nature of this property. These theories include various forms of hedonism about happiness, desire-satisfactionism about happiness, the life-satisfaction theory of happiness, Daniel Kahneman's theory of "objective happiness," and the emotional state theory of happiness (Feldman 2010; Davis 1981; Sumner 1996; Kahneman 1999). The phenomena central to all these theories are almost certainly closely related (Heathwood 2007; Gaus 1990; Katz 2008). But the main point, here, is that the target of all these theories is the same, and this target can be characterized in a theory-neutral way: it is the episodic feeling or experience of happiness, the feeling we attribute to people who are in high spirits, a good mood, who are feeling good, who are smiling (cf. Davis 1981, p. 305).

It does seem plausible that our normal use of the simple expression, "is happy," and especially the expression, "is happy now," frequently affords us socially-coordinated epistemic access to happiness in this episodic sense. That is, our use of these terms frequently enables us to focus our attention on "feeling good"- to think about it, to point it out to one another, to exchange information about it. Two examples will illustrate this point. Suppose a young child, Ricky, is eating an ice-cream cone at a family picnic. Suppose he is completely absorbed in this activity. From time to time, a bright smile spreads across his face; then it is time for another lick. Upon observing Ricky, it would be perfectly appropriate to say, "Ricky is happy right now." Or: suppose that Jill is on the tennis court and that she is playing very well against an old rival. It is hardly easy: she is running from one end of the court to another, saving balls that a lesser player would have let fly by. Any bystander can see that she is completely focused on the game, that she is confident and proud of her playing. She prevails in a series of five matches, shakes her opponent's hand, and laughs: "That was fun! We'll have to do that again, soon!" Surely, it is correct to say that Jill is happy at this moment.

According to one well-known, naturalistic understanding of conceptual analysis, if our use of the predicate, "is happy," is predominantly regulated by the property of episodic happiness; and if this property is itself internally unified, so that it is not gerrymandered or disjunctive; and if this property features in true and useful predictions and explanations, then there is every reason to say, quite simply, that the term "happiness" expresses this property (Boyd 1999).

However, things may not be quite so clear-cut. Philosophers such as Daniel Haybron hold that at least some uses of "is happy" conventionally express a different psychological property, the property of being deeply or robustly happy (2008, p. 147). This proposal is 
motivated, in part, by the great importance that ordinary people attach to happiness as a life-goal. This form of deep or robust happiness is conceived as an "emotional condition" (2008, p. 128). Emotional conditions are hypothesized by Haybron to be more stable than states, emotions, and moods; they are also more central and broad, because they involve dispositions to respond to the events of one's life in certain characteristic ways. However, emotional conditions are conceived to be importantly different from temperaments, traits (as discussed by personality psychologists), and "set-points" (2008, pp. 123-126, p. 134; cf. Diener and Lucas 2009). Emotional conditions persist for shorter intervals of time than traits (for days, weeks, and months, as opposed to years), and they may alternate over time with emotional conditions of the opposite valence. They are also highly sensitive to lifecircumstances and environmental changes, even though they persist over days, weeks, and months as underlying determinants of behavior. They are presumably not genetically determined, but rather the sorts of things that can be invoked to explain medium-term emotional differences between genetic duplicates. Similarly, they can be invoked to explain an individual's medium-term departures from their happiness set-point. Haybron characterizes the emotional condition of deep or robust happiness as a "mood propensity" in virtue of which one

$\ldots$ is prone to take greater pleasure in things, to see things in a more positive light, to take greater notice of good things, to be more optimistic, to be more outgoing and friendly, and to take chances more. One is also slower and less likely to become anxious or fearful, or to be angered or saddened by events. One confronts the world in a different way from the unhappy (2008, p. 139).

To distinguish it from episodic happiness, let us call this property, "happiness in the personal attribute sense." This property, too, might be analyzed in a variety of ways. According to Haybron's own theory, this form of happiness involves:

... a broadly positive emotional condition, with only minor levels of negative emotional response. "Broadly positive" means positive across the three modes of emotional response, in descending order of importance: attunement, engagement, and endorsement. To be happy, then, is for one's emotional condition to be broadly positive-involving stances of attunement, engagement, and endorsement-with negative central affective states and mood propensities only to a minor extent (2008, p. 147; emphasis in original).

These three modes of emotional response should be understood as follows. Attunement involves peace of mind or tranquility and confidence. It also involves "uncompression," which occurs when a person is not harried or anxious, not striking a defensive posture, but emotionally open and feeling at home in the world. Engagement involves taking an active interest in the events of one's own life, being energized, and being attentive. The "flow" experiences described by Csíkszentmihályi (1990), for example, are forms of engagement. Finally, endorsement involves positive emotions, especially joy and cheerfulness. When these stances define one's emotional condition, so that they are the norm for one, they count as central affective states. The more persistent (i.e., stable and robust), pervasive (i.e., diffused throughout the whole of consciousness), profound (i.e., characterized by a visceral phenomenal feel), and causally dispositive these states are, the happier one is.

This is not a "disconnected heap" of attributes, according to Haybron, because when these attributes are co-present in an individual, they have a special set of causal consequences (2008, p. 135). In particular, this complex state disposes individuals to experience certain other affects, and to sustain, broaden, and build on their good fortune (2008, p. 130, 
p. 132, p. 135, p. 144). Haybron also hypothesizes that this state involves an "underlying endogenous condition" (2008, p. 135).

It cannot be denied that the individual components of this state are real, or that they have been overlooked by many theorists of well-being. However, it is ultimately an empirical question whether there is an emotional condition like this, and whether its various components, when jointly present to the requisite degree, have the additional causal powers hinted at by Haybron. One reason for caution on this point is that a component of attunement seems to be in tension with engagement. It seems possible to be engaged-i.e., stimulated, active, alert, enthusiastic, lively-while also being confident and uncompressed. But the aspect of attunement called "peace of mind" and frequently glossed by Haybron as "tranquility" does not seem like it could coexist with the central affective states constitutive of engagement at a given time. Engagement is a high-activation emotional state; calmness and tranquility are low-activation mental states commonly classed alongside stillness, idleness, and passivity (Larsen and Diener 1992). These states could be present only in alternation or cycle.

Furthermore, it is not clear that this property is the ordinary and dominant sense of the term, "happiness." On Haybron's theory of this property, being happy at a time requires being attuned, being engaged, and being cheerful and joyous (2008, p. 147). But in ordinary English, it is correct to describe a person as happy even if they do not exhibit all these characteristics. Our tennis player, Jill, might be correctly described as happy while playing tennis, or at the moment that she wins the game, even though she is poorly attuned (e.g., dispositionally worried, guilt-ridden, and excessively defensive) off the court. Similarly, an individual could be correctly described as happy while daydreaming in a hammock on a warm summer afternoon — or while feeding the ducks in his or her back yardeven though he or she feels completely alienated from his or her work, marriage, and country of residence. Haybron seems to hold that such individuals are not happy: "Intuitively, a troubled, anxious, tense, or stressed out person-more broadly, someone who does not seem psychically at home in his life-does not seem to be happy, however cheerful he might be" (2008, p. 117). Later, he adds, "No amount of cheery feelings could, it seems, make up for a troubled soul" (2008, p. 141)

It is not clear that Haybron is correct on these points. It seems more likely that the term, "happiness" can alternately be used to express either episodic happiness or happiness in the personal attribute sense. While episodic happiness is perhaps the dominant sense of the term, there may also be a significant practice according to which it expresses deeper or more robust happiness. Claims like the ones made by Haybron in these quoted passages might sound false with one sense in mind, but true with the other sense in mind. This understanding of the situation accords with the findings of a recent psychological study, where the most popular answers to the question, "What is happiness for you?" fell into these two categories: harmony and balance, which also included feelings of inner peace, positive relations with oneself, contentment, and serenity, and emotions and feelings, which included joy, "temporary happiness," cheerfulness, being merry, euphoria, and moments of pleasure (Della Fave et al. 2011a, p. 194). The first of these categories corresponds closely to happiness in the personal attribute sense, and the second corresponds closely to episodic happiness. If "happiness" can be alternately used to express both of these phenomena, and both these phenomena are internally unified so that they feature in true and useful predictions and explanations, then researchers in philosophy, psychology, economics, and related fields should simply adopt technical terms to distinguish these properties-as has been done, here. 


\subsection{The Property of Well-Being}

There is considerably more agreement among philosophers about the basic contours of the property of well-being or welfare (Feldman 2010, pp. 160-170). A person enjoys high levels of personal well-being or welfare when their life is going especially well for them. Even if the life high in personal well-being requires moral virtue (a possibility that we will take up in Sect. 5), the welfare-value of an agent's life is conceptually distinct from its moral value: a given life might be great for the world but terrible for the person who lived it. The welfare-value of a life is also distinct from its aesthetic value-e.g., how pleasing of a story it would make, how interesting it would be as an object of contemplation.

Crucially, well-being is closely connected with the concepts of benefit and harm. When a person, S, benefits a person, T, S has thereby positively impacted T's level of well-being; when S harms T, S has diminished T's level of well-being (cf. Bond 1988). Welfare is, additionally, the master value for traditional accounts of moral rightness such as ethical utilitarianism (which directs one to maximize the welfare of all) and rational egoism (which directs one to maximize one's own well-being), and it plays an explanatory role in those versions of virtue ethics that identify virtues as traits that one needs in order to fare well. Furthermore, well-being is conceptually connected with the virtues of benevolence and kindness (Feldman 2010). It is also conceptually connected with attitudes of personal care and personal concern: if some condition is non-instrumentally good for a person, then if a friend cares for that person, the friend has a reason (of proportionate strength) to desire that the person be in the good condition simply for that person's own sake (cf. Darwall 2002). More controversially, some have held that considerations of well-being provide direct, normative reasons for action (Haybron 2008; Tiberius and Hall 2010).

The goal of a theory or analysis of well-being is to characterize the deep nature of the phenomenon that fits this basic characterization. There are several popular theories of well-being. These include versions of hedonism (Feldman 2004), desire-satisfactionism (Murphy 1999; Heathwood 2006; Lukas 2010), the Objective List Theory (Arneson 1999), aim-achievementism (Scanlon 1998; Keller 2009), developmentalism (Kraut 1979), the life-satisfaction theory (Sumner 1996), the self-fulfillment theory (Haybron 2008), and the capabilities approach (Sen 1993; Nussbaum 2006; Sen 2009; Nussbaum 2011). These are not, strictly speaking, different "meanings" of well-being or different "concepts" of well-being; they are all competing theories or accounts of the same concept.

\subsection{Argumentative Strategy}

In the next section, it will be argued that happiness in both the episodic and personal attribute senses is conceptually, metaphysically, and empirically distinct from well-being. However, the arguments used in this section to establish these points do not rely upon any particular theories or analyses of happiness or welfare. Rather, they are constructed so that, no matter which theory of episodic happiness, happiness in the personal attribute sense, or well-being one subscribes to, one will feel their pull. Indeed, if any particular theory of happiness or well-being was incompatible with the claims relied on in this section, then that would tend to show that that particular theory was false.

Then, in the subsequent section, it is argued that a particular theory of well-beingwell-being as agential flourishing-offers a good explanation of when and why episodic happiness and happiness in the personal attribute sense are directly beneficial. In the final section, it is argued that this theory also explains why the pursuit and achievement of goals, mental health, and feelings of personal expressiveness are intimately connected with 
well-being and happiness, as has been maintained by psychologists operating in the eudaimonic tradition.

\section{Two Proposals Concerning the Relation Between Happiness and Well-Being}

Some have proposed that what ultimately makes for well-being is episodic happiness, so that a person is necessarily well-off at a time to exactly the degree that they are experiencing episodic happiness at that time. Others have proposed that degree of happiness in the personal attribute sense can serve as a "proxy" for degree of welfare. (This is interpreted to mean that, while this robust form of happiness and well-being are ultimately distinct phenomena, a person's degree of happiness will approximate their degree of welfare; these two phenomena are positively correlated to the highest degree.) Here, it will be shown that neither of these two proposals is adequate.

\subsection{Episodic Happiness as the Sole Determinant of Well-Being}

Fred Feldman endorses the view that what ultimately makes for well-being is episodic happiness:

$\ldots$ it is ultimately only happiness [in the episodic sense] that determines welfare. On this view, the welfare value that a person enjoys or suffers at a time is directly proportional to her level of happiness at that time; the amount of welfare that a person enjoys or suffers during an interval is proportional to the amount of happiness that she has during that interval; the welfare value of a person's life as a whole is proportional to the amount of happiness in her life as a whole. More succinctly: welfare tracks happiness (Feldman 2010, p. 169).

Feldman calls this view "eudaimonism," though it should be carefully distinguished both from Aristotelian eudaimonism (e.g., Annas 1993) and the aforementioned eudaimonic tradition in contemporary psychology (e.g., Ryan and Deci 2001). Feldman's idea is that welfare tracks episodic happiness because welfare and episodic happiness ultimately consist in exactly the same thing-even if the terms "is happy" and "is well-off" differ in meaning.

There are several superficial indications that welfare does not track episodic happiness. We might in principle discover a person's level of episodic happiness at a particular instant by examining their current psychological state. However, a person's level of well-being at a time also appears to depend on their recent history; while their current psychological state is certainly relevant, it is not definitive. Consider a man whose car has just been hit by the car of another driver, but who is not injured. According to many theories of episodic happiness, the only things that are relevant to his current level of episodic happiness are his beliefs and attitudes at this instant. But his level of well-being at this time intuitively depends on many other factors. If we were to learn that he is flourishing in his work and his marriage, that he has many loving family members and friends, that he has hobbies that bring him great joy, and that he is seldom affected by pessimism or burdensome emotions like guilt, remorse, jealousy, and hatred, we might conclude that he is in fact quite well-off even at this moment, though he is certainly not very happy. This sort of case appears to show that welfare at an instant does not track episodic happiness at an instant.

However, it might be argued that welfare over a longer stretch of time is proportional to the amount of episodic happiness experienced over that stretch of time. There are possible 
cases that cast doubt on this view. Ronald Dworkin presents one such case in his book, Life's Dominion. Dworkin argues that, when administering end-of-life care, it is important to respect the last decisions made and expressed by patients while they were still competent. In this context, he describes Margo, a 54-year-old Alzheimer's patient. Margo's condition is quite tragic. She cannot accumulate new memories. If not locked in her own apartment, she will slip out at night and wander in the park in her nightgown. She does not recognize some of the members of her immediate family. She cannot remember the name of her personal care attendant. She cannot remember what place she is at in her book: she sits and hums to herself, rocking back and forth, and occasionally turns the pages. She attends an art class, where she draws the same picture every time. She loves peanut-butter and jelly sandwiches, and visibly takes great pleasure in eating them. Margo's personal care attendant writes that "despite her illness, or maybe because of it, Margo is undeniably one of the happiest people I have ever known" (Dworkin 1994).

Dworkin endorses the radical idea that people should be allowed to write advance directives requesting active euthanasia if they become demented or otherwise incapacitated. On his view, these directives should be strictly followed, even if doing so means terminating a happy life like Margo's.

In the present context, this case has a different significance. Margo truly might be one of the happiest people that her personal care attendant has ever known. She appears to be experiencing a preponderance of positive moods and emotions. She takes enjoyment and delight in her various activities and is not apparently pained or frustrated by her condition (indeed, it is uncertain that she can clearly conceive of her condition). There is no reason to doubt that she desires to perform her simple activities or that she wishes for the phenomenal experiences associated with these activities to continue. On any plausible theory of episodic happiness, she would seem to be quite happy. But most will agree that she is not well-off; she is not doing or faring well.

Of course, Margo's life might be going as well for her as a life afflicted by Alzheimer's can. But it is important to recognize that this is not to say that she is doing or faring well simpliciter, or that she is doing or faring well as a human person. If it were, then we could truthfully characterize her transition to this state as something that benefited her very much, so long as her earlier life contained less happiness than her current life (which again seems likely, if her personal care attendant's assessment is to be trusted). If Feldman's "eudaimonism" were true, then it would also follow that those who care about Margo, in virtue of their caring about her, had a reason to desire (for her sake) that she become afflicted with Alzheimer's, and that they currently have a reason to desire (for her sake) that she persist in her current condition for as long as possible. But if we presented this reasoning to Margo's friends and family members, they could only regard it as a cruel joke. This case shows that we should reject the thesis that welfare tracks episodic happiness.

Now, it might be protested that Margo, when her Alzheimer's advances to a sufficient degree, is no longer the same person that she once was, and so no longer the same welfare subject. Perhaps when her Alzheimer's is sufficiently advanced, Margo ceases to exist. This would be one way in which a theorist like Feldman might avoid the counterintuitive conclusions just described. However, this response comes at a high price: if Margo ceases to exist when her dementia is sufficiently advanced, then becoming afflicted with Alzheimer's does not harm her in the ways we ordinarily believe that it does, either. Views of personal identity according to which Margo ceases to exist ought to be resisted. Instead, we might construe personal identity-or rather "prudential unity," the basis of self-interested concern-as a matter of degree (McMahon 2002). To the degree that two temporal stages of an entity are unified by important psychological connections-lived 
experiences and memories of these, as well as stable values, intentions, and beliefs- they are prudentially unified. If this approach to personal identity is basically correct, and if Feldman's "eudaimonism" is true, then the benefit to Margo of coming down with Alzheimer's must be discounted on account of her diminished psychological connectedness to her later temporal stage. Still, if happiness tracks well-being, then the benefit of the transformation brought about by the disease could be substantial, given how happy the later Margo is. But this is not plausible. Forced to choose between this promising account of the bases of self-interested concern and Feldman's "eudaimonism," it is best to reject the latter.

\subsection{Happiness in the Personal Attribute Sense as a Proxy for Well-Being}

Margo's degree of happiness is greater than her degree of well-being. For this reason, it would not be plausible to claim that episodic happiness is a "proxy" for well-being, i.e., that a person fares well to approximately the degree that they are happy. However, it might be thought that the problem with Margo's happiness is that it is shallow. If we were talking about a deeper form of happiness that involved more complex behavioral dispositions-a form that is perhaps unavailable to Margo on account of her cognitive limitations-then perhaps we could maintain that happiness is a proxy for well-being. This is precisely what Haybron proposes: a person fares well to approximately the degree that they exhibit happiness in the personal attribute sense, and this is why "knowing that someone is happy normally licenses an inference that the person is well-off" (Haybron 2008, p. 150; p. 139). Recall that, if one is happy in the personal attribute sense, then one takes greater pleasure in things, is more perceptive, is more optimistic, is more outgoing and friendly, takes chances more often, and is slower and less likely to become anxious, fearful, angry, or despondent (Haybron 2008, p. 139). According to Haybron's particular theory of the deep nature of this property, "To be happy... is for one's emotional condition to be broadly positive - involving stances of attunement, engagement, and endorsement-with negative central affective states and mood propensities only to a minor extent" (Haybron 2008, p. 147).

There are possible cases that indicate that happiness in the personal attribute sense is not a proxy for well-being. Suppose that Robert, after many years, is laid off from a managerial position at a large company. On account of his age and experience and the general economic conditions, it is unlikely that any other firm will hire him. For many months, he sits at home, reflecting on his lot in life. He has very little money saved for his retirement, and his house is falling apart. His wife left him years earlier, and his children have moved away to distant cities. He is deeply depressed. Suffering from a respiratory infection, he sees a doctor at a free clinic. After attending to Robert's respiratory problems, the doctor begins asking him questions. As a result, Robert receives a prescription for a new antidepressant.

After using this drug for two weeks, Robert begins to feel much better: there is a marked change in his mood. Nowadays, he is always smiling and jolly. He gets out of the house everyday. He tells his friends that he feels calm at last, after years of stress and worrying. He reports that he has a sense of deep personal well-being. He spends money very freely. When banks and credit firms call to complain about his delinquent bills and tell him about the pending repossession of his car and the foreclosure of his home of twenty years, he says "Ooo! That sounds bad. I mean, it sounds serious," and then he chuckles, "I guess I'm in trouble." But he continues to live in a carefree way. When people ask him how he's doing, he says, "I feel great!" When his sister calls to tell him about the death of his beloved older brother, he says, "Oh, that's too bad," and continues in the same breath: "Say, do you want 
to catch a movie tonight? Maybe we could go out to eat? They've got this great shrimp dish over at Applebee's."

Such cases may be extraordinarily rare in reality; perhaps few widely-used drugs have effects like these. Even if some drugs do have effects like these when administered under certain conditions to certain individuals, such cases will be rare and temporary in countries where healthcare is publicly funded and easily available, and where physicians closely monitor their patients' responses to therapies. But even the rare and temporary possibility of such cases suggests that robust happiness is not a reliable proxy for well-being. For it seems that Robert's medication has greatly improved his happiness in the personal attribute sense: he is now more attuned, more engaged, and more cheerful. But this course of medication does not seem to have benefited him; he is not doing well, now, he is doing badly. Those who care about him thereby have a reason to help him change his medication. Happiness in the personal attribute sense does not track well-being and is not a proxy for it. At most, such happiness might be a necessary-but not a sufficient-condition for especially high levels of well-being, so that in order for a person to be doing exceptionally well, they might also need to be happy in the personal attribute sense.

In a later chapter of his book, Haybron introduces a qualification that may be thought to supply a response to the counter-example just proposed. He writes that:

... well-being has other aspects even as happiness remains central: self-fulfillment requires authenticity... Authenticity... seems to require proper functioning, at least within broad limits: someone whose brain is pathologically stuck on 'happy,' no matter what happens or what she thinks, is not credibly viewed as authentically happy (2008, p. 186).

In addition to "proper functioning," authenticity also requires, according to Haybron, that one's desires to be "well enough" informed. One's happiness must be based either on desires that are not "manipulated or otherwise non-autonomous," or else on one's own nature or temperament. Furthermore, one's happiness is more authentic to the degree that it is "grounded in richer, more complex ways of living" (2008, pp. 185-186). The view expressed in this passage, then, seems to be that authentic happiness (in the personal attribute sense) is a proxy for well-being. Robert's happiness, despite it being deep and robust, is not authentic; that is why we cannot readily infer that he is doing or faring well.

This view poses a number of difficult questions. Under what conditions should we say that a desire is uninformed, manipulated, or non-autonomous? Is it correct to think of people as having well-defined individual natures or temperaments? Why should richer and more complex ways of living be counted as more authentic? Is it not possible for a person whose nature and contingent values are shallow and simple to fare well by living a shallow and simple life? How are we to understand "proper functioning"? In particular, what is the relevant standard for properness? These questions are left unanswered. The view that authentic happiness is a proxy for well-being may not be false. But, while Haybron presents a very detailed and sophisticated explanation of happiness as a personal attribute, his account of authenticity is quite underdeveloped. While Haybron appeals to proper functioning at several other points-e.g., to explain how depression is sometimes beneficial (p. 115), to explain basic needs and the priority of attunement (p. 121), and to explain "psychic flourishing" (pp. 147-148)—he does not spend much time explaining this concept or the standard(s) relevant to it.

The next section presents a theory of well-being that allows us to correctly explain when happiness is welfare-constituting. This theory also furnishes a standard for appropriateness of emotional response and a more detailed and specific conception of "proper 
functioning." Consequently, if conjoined with some of Haybron's formulations, it may license something like his claim that authentic happiness in the personal attribute sense is a proxy for well-being.

\section{The Relation Between Happiness and Well-Being}

It is obvious that neither Margo nor Robert is doing well. We can explain why-and more generally explain the connection between happiness and well-being-if we adopt the view that well-being consists in agential flourishing. This section presents this view, describing its key components in order. While it is not possible to present the complete case for the view here, or to answer every reasonable objection, if the connection this view posits between happiness and well-being has explanatory power, it will have been shown that there is important evidence in its favor, so that it is worthy of further development and attention.

\subsection{Well-Being as Agential Flourishing}

Well-being as agential flourishing states that an adult human person is doing well at a time to the degree that they resemble the paradigm case of the flourishing agent at that time. ${ }^{2}$ The paradigm case of the flourishing agent is a person who successfully realizes their values and is stably disposed to do so. This person must have values, must desire to realize these values, and must possess a body and mind that are suitable for efficacious action on behalf of these values. Furthermore, this person must actually pursue and realize these values through their own effort-and experience appropriate emotional feedback on this entire process. The paradigmatically flourishing agent's valuational and motivational systems function fruitfully and harmoniously.

Any change in a person's condition that moves them further away from this paradigm is directly bad for them at the time of its occurrence; any change that moves a person closer to this paradigm is directly good for a person at the time of its occurrence. The degree of harm or benefit, here, is proportional to the degree to which the person has been moved closer to-or further from-the paradigm. ${ }^{3}$

Let us consider the most important elements of agential flourishing in order.

First, the flourishing agent has and strives to realize their personal values. Values are the objects of valuing as an activity, and they may include states-of-affairs, ideals, persons, relationships, and even artifacts. To value something, one must first genuinely like, desire, or enjoy the thing in question: one must have some stable pro-attitude towards it. Second, one must be stably disposed to identify with this pro-attitude. To identify with a proattitude, one must have the sense that one's attitude expresses both who one is and who one

\footnotetext{
2 This theory attempts to explain the welfare of adult human persons, not the welfare of all possible welfaresubjects or all possible rational beings (it is not clear to me why many philosophers assume that such a general theory of welfare is possible). The theory explains welfare at a time, but it can also be extended to provide estimates of welfare over time and the welfare-ideal human life. It can also be extended to explain the welfare of children. Space limitations prohibit discussion of these extensions, here.

3 This theory attempts to explain the deep nature of personal benefit and harm; it does not furnish us with any kind of prudential decision-procedure that would allow us to tell which course of action would bring us closer to the paradigm. But, if the theory correctly identifies the "target"-i.e., the deep nature of welfarepsychologists and others who know the relevant empirical facts could presumably identify principles or rules for approaching it.
} 
aspires to be (Frankfurt 1998; Tiberius 2008). But identification also involves behavioral dispositions. In particular, one must be disposed to treat facts about the valued item as reason-providing in one's practical deliberations (Bratman 1996). It is likely that, to stably identify with an attitude, one must have an approximately correct understanding of its object's nature, as well as some measure of self-awareness (cf. Brown and Ryan 2003). For reflective persons, stable identification will probably require a disposition to believe that the pursuit and attainment of the valued item complements one's other values. Valuing that involves both a stable pro-attitude towards an object and stable identification with this proattitude will typically involve non-instrumental concern for the valued object; it does not make sense to say that one enjoys, cherishes, or loves something "merely as a means."

Second, agency involves actualizing, promoting, protecting, or maintaining one's values through one's own action. To succeed as an agent is to actively realize one's values. Realization may involve promoting abstract values that are important to one, like freedom or equality. Or, it may involve actualizing states-of-affairs that one deeply desires, e.g., writing a book or achieving a promotion at one's work. Realization may also involve nurturing loved ones, protecting or safeguarding the things one cares about, or nourishing one's personal relationships. Agential success is broader than the ordinary notion of achievement. First, it is a stretch to characterize a relationship, a friend, or a loved one as a goal, though these things can obviously be values. Second, "achievement" may connote competition or the accomplishment of a novel, difficult, or rare feat. By contrast, on the present view, values can be quiet, non-competitive, and unsophisticated; agential successes may be private and not especially novel or challenging. Note also that values-realizations can be contributions to group efforts or activities, fulfillments of socially defined roles, or accomplishments of pro-social goals. For this reason, there is no necessary conflict between an individual's flourishing as an agent and the common good, provided that the pro-social values (e.g., helping others in need, improving one's community, spending time with friends and family) that are pursued and realized are ones with which the relevant individuals identify.

In order to truly flourish as an agent, one must do more than successfully realize one's values. One's valuational and motivational systems must be functioning in a particularly robust way, so that one is stably disposed to realize one's values to a sufficient degree. In particular, one must be ready to cope with the various forms of adversity that one is likely to encounter in the pursuit of one's values, and one must be poised for further success. In order to count as having these dispositions, it is probable that one must develop certain mental aptitudes and habits and enjoy a variety of states ordinarily associated with good physical and psychological health. These states constitute the causal basis for the disposition to realize one's values. ${ }^{4}$ It is therefore directly—as opposed to instrumentallybeneficial to be in these states.

To be sufficiently disposed to realize one's values so as to count as flourishing as an agent, one must cultivate certain habits of mind. These include rationality, where this is understood as being oriented towards the facts, open to new evidence, and (more generally) reasoning in truth-conducive ways. Additionally, self-awareness is not only necessary for having stable pro-attitudes, as described above. It also strengthens one's disposition to realize one's values, as it enables one to appraise one's aptitudes and one's progress in values-oriented activities and make necessary modifications either in one's priorities or

\footnotetext{
4 The disposition to realize one's values is constituted both by some non-dispositional or "categorical" properties and by some further dispositions; hence the reference to its causal basis rather than its categorical basis (Prior et al. 1982; Fara 2006).
} 
one's actions (Tiberius 2008). Other habits of mind may also be important in this contexttheir identification is a task for further research.

To count as flourishing as an agent, one must also have a body that renders one capable of efficacious action on behalf of one's own values, whatever these happen to be. Other things being equal, one's disposition to realize one's values is strengthened by the maintenance of bodily systems that enable one to causally influence the world and achieve environmental mastery (cf. Ryff and Keyes 1995). One's ability to cope with adverse circumstances is diminished if one loses (e.g.) a limb, one's sight, or one's hearing. But this does not imply that individuals who become disabled cannot flourish as agents, and it certainly does not imply that disabled individuals have diminished moral status. If a person is disabled during the course of their life, it is likely that, at the time their disability occurs, their disposition to realize their values will be undermined, so that they will have a lower welfare level than an otherwise similar individual who did not become disabled. However, if, after becoming disabled, a person adjusts their hierarchy of values, so that their new hierarchy requires the abilities that have been compromised to a lesser degree, this will mitigate the harm caused by their disability. If such a person successfully realizes their new values and cultivates a strong disposition to do so, perhaps by drawing upon previously untapped psychological resources, they might be doing or faring very well. The same could be said, for instance, about those whose abilities deteriorate as a consequence of aging, but who "grow old gracefully" by reordering their priorities and discovering new interests so that their values better match their capabilities. Finally, it should be emphasized that, even if a person has been greatly harmed by their disability or by the process of aging, this does not imply that they can be treated in prejudiced or discriminatory ways. A person's level of welfare is one thing; their moral standing, status, or worth is something else, entirely.

Flourishing as an agent not only requires a certain physical condition; it also requires a certain psychological condition. This condition consists not merely in the absence of mental illness but in the presence of various stances, dispositions, and abilities (cf. Keyes 2007). First, one needs a basically cheerful, upbeat, energized emotional disposition-a stance of engagement, exactly as Haybron describes it. While anxiety, dread, and compression seem to threaten the disposition to succeed, confidence, optimism, and selfesteem underwrite it. Second, the aspects of positive psychological functioning described by Ryff, Keyes, and their colleagues all seem important in this context (Ryff and Keyes 1995; Keyes et al. 2002). These include self-acceptance (acknowledging and accepting multiple aspects of the self, including limitations), positive relations with others (a desire to develop and maintain trusting relationships with others), a sense of self-determination (the ability to resist social pressure and independently assess situations, including oneself and one's actions), a sense of purpose in life (having goals, a sense of directedness, and a disposition to find meaning in efforts and challenges), and openness to personal growth (openness to continued development in light of new experiences and change). All these properties plausibly strengthen one's disposition to realize one's values. But purpose in life and personal growth seem especially important, as these ensure that one maintains and generates new values over time.

Additionally, to fully flourish as an agent, one must be disposed to certain patterns of emotional reaction. Emotions play several roles within our valuational and motivational systems. They give us feedback on our action, which feedback motivates us to try againor to cease trying. Emotions also alert us to the status of things we care about, thereby disposing us to appropriate future action. A properly functional emotional system-where the standard of "proper functioning" is supplied by the goal of agential success-usually dispenses positive emotions when a person is successful in maintaining or realizing their 
values, and negative emotions when a person's values are threatened, or when they fail or suffer physical or psychological damage. It can be directly beneficial for a person to experience negative emotions, provided that these are not so overwhelming that they actually dispose a person to disengagement, inaction, passivity, and the like. However, the proper functioning of the emotional system (from the point of view of welfare) does not require exact apportionment of negative affect to failure and damage. When we are faced with matters that need our immediate attention, and it would be paralyzing to experience emotional suffering in proportion to the harms that our values have sustained, it is beneficial for emotions to be dulled.

Well-being as agential flourishing has noteworthy similarities to other theories in the philosophical literature. It is a subjective view of well-being insofar as it ties one's welfare to one's own cares and concerns (Sumner 1996, p. 42). It is a conative theory of wellbeing, because it explains welfare-value in terms of valuational and motivational states. It differs importantly, though, from actual desire-satisfactionism about well-being, because it holds that the fulfillment of a desire-e.g., the scratching of an itch-is far less important for one's well-being than the realization of a value. Simultaneously, it is broader than the current versions of aim-achievementism, because it says that goals are just one example of the values that are relevant to one's well-being. It is not just when one's goals are impeded or frustrated, but also when one's values are impeded or destroyed, that one is directly harmed. The view also differs from extant conative theories in its holism: it does not identify atoms of welfare whose values can simply be summed. It requires us to compare a person as a whole to the optimally functioning agent, taking full account of the interrelations among the various aspects of a person's psychological state and physical condition. Finally, like Amartya Sen's capability approach, this theory treats dispositional states as directly beneficial and harmful. However, Sen analyzes individual advantage in terms of a person's capability to do things and not in terms of their actual achievements (Sen 2009). ${ }^{5}$ By contrast, degree of agential flourishing depends both on one's actual value-achievements and on one's dispositions to achieve one's values. Furthermore, unlike Sen's capability approach, the present theory concentrates on one's actual values, as opposed to the things that one has reason to value.

\subsection{Well-Being and Happiness}

Well-being as agential flourishing correctly implies that neither Margo nor Robert is faring well. Margo departs markedly from the paradigm of the flourishing agent, because she does not truly have values, as her condition prevents her from stably identifying with her proattitudes, in part because she cannot intend to treat these attitudes as reason-providing over longer periods of time. Similarly, Robert departs from the paradigm because his ability to promote or safeguard the things he cares about is undermined by his pattern of emotional reaction. While he is happy in both the episodic and personal attribute senses, his emotional reactions do not dispose him to cope with threats to his values, or to repeat or build on his successes. Rather, they dispose him to fail, much like the sensory apparatus of an individual with congenital analgesia.

However, if we adopt an emotional state analysis of episodic happiness, then well-being as agential flourishing implies that episodic happiness is directly beneficial in many contexts. Haybron points the way towards such an analysis of episodic happiness (though his

\footnotetext{
5 Sen (1985) suggests a different view, one according to which achieved well-being consists partially in achieved functionings, as Nussbaum notes (2011, p. 198).
} 
main goal is to analyze happiness in the personal attribute sense). He writes, "To be happy... is for one's emotional condition to be, on the whole, positive. That is, the overall balance of one's moods and emotions is positive rather than negative; positive emotions and moods outweigh the negative" (Haybron 2008, p. 109). We might further develop this view as follows: the relevant positive moods and emotions are those on the "pleasant" axis of the affect circumplex (Russell 1980; Larsen and Diener 1992). These include, most centrally, joy, cheerfulness, and delight - the very states Haybron grouped under the label, "endorsement." Other emotional states-e.g., joviality, jubilance, elatedness, glee, gaiety, gratification, satisfaction, contentment, exaltation, bliss, ecstasy-may contain joy, cheerfulness, or delight as central parts. The relevant negative moods and emotions would correspond to the items on the unpleasant axis of the affect circumplex: sadness, misery, grouchiness, gloominess, and blueness. Related emotional states containing these negative emotions as parts or aspects might include bitterness, grimness, dread, uneasiness, distress, perturbedness, agony, grief, anxiety, irritability, dissatisfaction, and anguish. The emotional state theory of episodic happiness would then hold that $S$ is happy at a time just in case $\mathrm{S}$ experiences a preponderance of the positive moods and emotions listed here at that time. Following Frederickson and Losada (2005), Haybron proposes that the ratio of positive emotions to negative emotions be at least 3-1 (Haybron 2008, p. 141). This or some other ratio could be specified. ${ }^{6}$

These emotional states can underwrite or partially constitute one's disposition to realize one's values. They are also partially constitutive of certain forms of valuing as an activity. They are also characteristically valued. Consequently, well-being as agential flourishing implies that these states are often directly beneficial.

There are at least two ways in which these emotional states can serve as the causal basis for the disposition to realize one's values. In some cases, they partially constitute emotional states (or conditions) such as positivity and good cheer that themselves partially constitute the disposition to realize one's values. Such states (or conditions) make it more likely that one will value things, that one will deliberate reliably about how to realize one's values, and that one will have the energy and perseverance to act on their behalf. In other cases, feelings of happiness can serve as rewards: if a person experiences episodic happiness in the process of pursuing their values, or as a reward that accompanies their success, this happiness is directly beneficial, provided that it motivates further success. It therefore partially constitutes the disposition to succeed.

As already noted, some of the mental states that are forms of valuing are also happinessconstituting. For example, if a person enjoys sailing, that is the way in which they are valuing it: they are identifying with their enjoyment of it, and taking this enjoyment to be

\footnotetext{
${ }^{6}$ The emotional state theory does not face the objections Feldman has raised against Davis's desiresatisfactionist theory, Sumner's life-satisfaction theory, and Kahneman's theory of "objective happiness" (Feldman 2010, pp. 37-104). It also has an advantage over Feldman's own attitudinal hedonism, which does not capture the affective component of episodic happiness. Feldman in fact argues that happiness does not involve any affective component (Cf. Feldman 2010, pp. 143-147). Feldman argues that all a person's sensory feelings could be suppressed by anesthesia, and yet the person might still be quite happy. The problem with this argument is that Feldman has entirely ignored emotional or affective feelings, which are distinct from sensory feelings like warmth, cold, and pressure. Feldman is correct that it is possible for a person to be attitudinally pleased or happy without having any sensory feelings. But happiness requires the presence of positive emotional states — states which anesthesia does not characteristically suppress. A person who is attitudinally pleased to a high degree without experiencing any of the usual concomitant positive emotional states might count as notionally pleased, but they would not count as happy (cf. Zimmerman 2010).
} 
reason-providing. Since enjoying (construed as a form of valuing) seems to itself involve affective states that make for episodic happiness, these states are also directly beneficial.

Finally, and perhaps most obviously, most people value happiness: they like being happy, and they take this liking to be representative of who they are and want to be. For all such individuals, the cultivation of happiness is directly beneficial because it is valued.

Well-being as agential flourishing, conjoined with the emotional state theory, also explains the disvalue of episodic unhappiness. In large doses, sadness, misery, grouchiness, gloominess, and the like disrupt one's ability to hold values. In many contexts, they also lower the likelihood that one will realize the values one has. The theory therefore accords with the commonsense view that, if a person is very unhappy, day after day, their life cannot score high in welfare-value. Even if such a person developed and exercised all their various capacities, each to a truly exceptional degree, if they were consistently unhappy, their success would be highly unstable, and they could not be doing especially well. ${ }^{7}$

Using this theory's analysis of direct benefit and harm, we can also show that many of the states that constitute Haybron's happiness in the personal attribute sense are directly welfare-good. (Note that these states would appear to count as aspects of emotional wellbeing, even if they do not have the more robust causal profile described by Haybron.) We have already seen that cheerfulness and joy (two states classed as endorsement), particularly when taken in the pursuit or realization of one's values, can be directly beneficial. Appropriate confidence (one aspect of attunement) disposes one to succeed, at least if anecdotal evidence is to be trusted. Other things being equal, it is also true that to be energized, active, and attentive (states classed as engagement) is to be disposed to realize one's values.

The present model also explains why compression is so harmful. Being harried, anxious, defensive, emotionally closed off, or hunkered down-i.e., compressed—is very bad for one precisely because it is disruptive of values-formation and goal-directed action, as well as the other states just mentioned in connection with endorsement, attunement, and engagement.

What, though, about tranquility or peace of mind, one aspect of attunement (and therefore of happiness in the personal attribute sense)? If tranquility and peace of mind just come to the absence of anxiety, worry, irritability, and jumpiness - or to the presence of self-esteem, self-acceptance, and cheerfulness - then the present theory implies that these states are directly beneficial for reasons already described. If tranquility and peace of mind are understood as temporary states of mental relaxation that allow one to recuperate from activity and achieve perspective on one's life, then some alternation between these states and states of engagement is beneficial, since it is most conducive to successful functioning for creatures like us. Tranquility and peace of mind can also be valued for their own sake and sought through effortful activity, as they are by adherents of Hellenistic and East Asian ethical doctrines. Here, these states involve a hard-won inner calm that signifies mastery of one's emotions. They are valued states that are are pursued, maintained, and achieved through action - through control of one's thoughts and desires, meditative practice, and self-discipline. Consequently, at the process-level, they do not involve inactivity or stasis, but rather concentration and exertion.

\footnotetext{
7 It is therefore false that, if all of a person's major goals are being achieved, and a person knows this, then they will simply feel happy as a matter of nomological or causal necessity (cf. Kraut 1979). Even the greatest achievers - those who, against all odds, satisfy all their most important goals — might be afflicted by depression or anxiety and for this reason be seriously unhappy.
} 
However, if "tranquility" expresses a total inner peace or calm that can be effortlessly maintained, like the state brought on by the ingestion of Soma in Aldous Huxley's Brave New World, then tranquility is not directly beneficial. Rather than disposing one to valuessupporting activities, such tranquility would dispose one to stillness, stasis, passivity-and in the limiting case, death, which is a significant departure from the paradigm case of agential flourishing.

\section{Well-Being as Agential Flourishing and the Eudaimonic Tradition of Happiness Research}

Well-being as agential flourishing integrates insights from several extant eudaimonic models of welfare and happiness, and so it can claim the support that already exists for (these aspects of) them. Furthermore, the theory can answer several common criticisms of these eudaimonic models.

\subsection{Congruence with Eudaimonic Models}

Well-being as agential flourishing construes welfare as a process that has at its cores the pursuit of values with which the subject stably identifies. This is closely related to a postulate of Ryan and Deci's self-determination theory, viz., that well-being is an outcome characteristically promoted by the satisfaction of needs for competence (the propensity to have an effect on the environment and attain valued outcomes within it), autonomy (the propensity to self-organize experience and behavior and to have activity be concordant with one's integrated sense of self), and relatedness (the propensity to feel connected to others in loving and caring relationships) (Deci and Ryan 2000, p. 231; cf. also Ryan et al. 2008, Sheldon 2004). Ryan and Deci further hypothesize that individuals are naturally oriented towards the satisfaction of these needs, as well as toward "growth" and the "integration of their psychic elements into a unified sense of self and integration of themselves into larger social structures" (p. 229). These are among the values that are universal because "built into human nature" (2008, p. 148). When individuals pursue goals that intrinsically involve the satisfaction of such needs ("intrinsic goals"), their behavior will be characterized by choice and volition and the result will be high levels of lifesatisfaction, psychological health, self-actualziation, self-esteem, ego development, and other indicators of well-being (2000, p. 241).

The theory presented here holds that conditions that strengthen one's disposition to realize one's value are directly beneficial when attained. Whether or not competence, autonomy, and relatedness should be classified as universal and innate human needs, these propensities plausibly strengthen one's disposition to realize one's values. As analyzed by Ryan and Deci, competence just is robust and efficacious value-realization. Autonomy is a propensity towards self-organization; one is more autonomous to the degree that one's behaviors are governed by "identified regulation"-where the agent identifies with the value in question - and "integrated regulation" - where the agent identifies with the value in question and performs the relevant activity for its own sake. (Behaviors governed by integrated regulation are the most fully self-determined, according to Ryan and Deci.) While well-being as agential flourishing implies that the realization of values is always intrinsically benefical, it can also acknowledge that individuals whose activities exhibit integrated regulation are faring even better. In this case, durability of interest and continuous positive feedback are built into the process of valuing itself. Relatedness similarly 
enlarges one's resources and increases one's resilience, thereby serving as at least a distal support for the disposition to realize one's values; it is sometimes directly and sometimes instrumentally beneficial. Furthermore, since the stability of one's values is augmented by their synchronic and diachronic consistency and by their developmental continuity, the agential flourishing analysis also puts great emphasis on psychological growth and integrity, whether these are conceived as innate trajectories or not.

Finally, Ryan and Deci hold that pleasure and positive affect (which constitute episodic happiness) are determinants of welfare, because "they represent intrinsically preferred states, but also because they can facilitate and support other human functions" (p. 141). As noted in the previous section, well-being as agential flourishing recognizes episodic happiness as a direct determinant of well-being for these same reasons.

Carol Ryff's classic article "Happiness is Everything, or Is It? Explorations on the Meaning of Psychological Well-being" (1989) articulates and operationalizes a holistic vision of positive psychological functioning as distinct from the mere absence of illness. This paper, as well as many later collaborations with Corey L. M. Keyes and others (e.g., Ryff and Singer 1998; Ryff and Keyes 1995; Keyes et al. 2002), have emphasized the importance of what is variously called "psychological functioning," "psychological wellbeing," "challenged thriving," or "mental health." As already noted in Sect. 4.1, this state has six psychological dimensions: self-acceptance, positive relations with others, autonomy, environmental mastery, purpose in life, and personal growth. As was also described above, environmental mastery is supported by states associated with physical health, and all these states count as psychological aspects of the disposition to realize one's values. Purpose in life and personal growth speak to the need for a rich and continuously evolving system of values, which is necessary for flourishing as an agent over a normal human life-span.

Keyes has further built upon this work, specifying that the elements of Ryff's operationalization are symptoms of an endogenous state that is not directly observable (Keyes 2002) and presenting a complete state model of mental health, according to which health consists in SWB, the presence of positive psychological and social functioning, and the absence of disease or infirmity (2007). This composite state Keyes labels as "flourishing." This, too, closely resembles the agential flourishing account, which also posits complex reciprocal relationships between happiness in the episodic and personal attribute senses and highlights psychological aspects of the disposition to realize one's values. Some aspects of positive social functioning can also be incorporated into the present theory as distal supports for the disposition (and so, at a minimum, instrumentally beneficial). This is because positive relations with others are frequently valued for their own sake, as well as empowering. One will maximize one's opportunities for such relationships if one has positive attitudes towards others and is accepting of differences (social acceptance), sees the potential in others (social actualization), and is interested in society and social life (social coherence). Furthermore, one will likely have greater confidence in the worth of one's own values and activities if one perceives them as useful to and valued by others (social contribution), and if one has a sense of belonging to and support from a community (social integration).

Finally, the theory presented here has plausible implications about the connection between personal welfare and the feelings of personal expressiveness described by Waterman (1993). Waterman has long emphasized the importance of self-realization values for understanding happiness and well-being (1990). These are ends whose coordinate activities develop personal potentials and advance life goals. Waterman proposes that, when an agent identifies the nature of his or her best personal potentials, believes the development of these potentials to be worthwhile, and engages in activities that appropriately develop 
them, those efforts will, under most circumstances, be accompanied by feelings of personal expressiveness. These feelings are hypothesized to be subjectively distinguishable from episodic happiness and a reliable guide to identifying one's "best potentials."

To test for these feelings, Waterman asks subjects to rate activity-types (from "strongly disagree" to "strongly agree") on the following measures: (1) This activity gives me my greatest feeling of really being alive; (2) When I engage in this activity, I feel more intensely involved than I do when engaged in most other activities; (3) This activity gives me my strongest feeling that this is who I really am; (4) When I engage in this activity I feel that this is what I was meant to do; (5) I feel more complete or fulfilled when engaging in this activity than I do when engaged in most other activities; and (6) I feel a special fit or meshing when engaging in this activity (Waterman 2008, p. 51).

Waterman's research confirms that there is a very strong correlation between measures of hedonic enjoyment (ratings of activities as "enjoyed," "pleasant," "feeling good," or "giving rise to feelings of satisfaction ... or happiness") and these measures of personal expressiveness. There is also an interesting asymmetry: in a recent study, $88.4 \%$ of activities that scored high in personal expressiveness also scored high on measures of hedonic enjoyment, whereas only $67.9 \%$ of hedonically enjoyed activities were high in personal expressiveness (2008, p. 59). ${ }^{8}$ Furthermore, Waterman has shown that measures of personal expressiveness correlate highly with measures of the balance of challenges and skills, self-realization values, level of effort expended, and subjective importance, whereas hedonic enjoyment measures correlate more strongly with measures of autonomy (selection of the activity as chosen as opposed to required) and level of interest when engaged in the activity (2008, p. 63). ${ }^{9}$

Well-being as agential flourishing is neutral on the controversial question of whether measures of personal expressiveness are measuring introspectively identifiable feelings (Biswas-Diener et al. 2009). It is possible that they instead measure beliefs that activities are fulfilling, engaging, or expressive of the self: for the verb "to feel" and the noun "feeling" are often used to express the concept of belief in American English. Whether there are such feelings or not, since measures of personal expressiveness correlate highly with measures of self-realization and subjective importance, Waterman's work shows that activities expressive of personal values can be isolated and that such activities have interesting properties. For instance, those who engage in such activities almost always derive hedonic enjoyment from them. This finding is consistent with the role the agential flourishing analysis describes for episodic happiness as a component of welfare.

Well-being as agential flourishing will usually classify activities that give rise to feelings or judgments of personal expressiveness as directly beneficial to a high degree. If a person enjoys an activity, and they also experience the activity as giving rise to feelings of vitality, intense involvement, or fulfillment, and they furthermore believe it to be expressive of who they really are, then this activity (or the goal that it serves) will ordinarily count as one of their values. For feelings or judgments of personal expressiveness themselves constitute a form of identification with one's enjoyment. Such feelings

\footnotetext{
${ }^{8}$ Since all the activities rated by this study were ones that subjects picked out as representative of "who [they] are and what [they] are like as a person," it is also likely that there are other activities that are very enjoyable but that score much lower personal expressiveness, and so are less significant for welfare (just as the present model predicts).

9 Waterman et al. show empirically that autonomous selection is necessary but not sufficient for activities to exhibit the profile of characteristics usually associated with intrinsically motivated activities. On conceptual grounds, the theory defended here concurs that autonomous selection of goals is not sufficient for them to count as valued, i.e., as objects of pro-attitudes with which the subject stably identifies.
} 
will also make it more likely that the activity is stably valued over time. Consequently, in pursuing an activity that gives rise to these feelings, the individual is usually realizing a value and thereby brought closer to the paradigm of agential flourishing. If most of a subject's activities give rise to feelings or judgments of vitality, involvement, fulfillment, and self-expression, this is a reliable sign that they are flourishing as an agent and doing or faring well.

However, the theory presented here also predicts that high measures of personal expressiveness across all these items (1-6) are not necessary for an activity to be beneficial when pursued. For example, item 4 seems to require that one feel or believe that one was "meant" for the relevant activity. While this can be read in more or less metaphysically loaded ways, some subjects may read it as requiring belief in a "true self" that is unique from all other selves, that has a permanently fixed nature, and that has been waiting all along to be developed (cf. Norton 1976). A person need not think of activities as expressive of such a "true self" in order for the activities to expressive of deeply held values.

It is also noteworthy that a particular activity might give rise to intense feelings of personal expressiveness while being inextricably linked with low levels of overall wellbeing. Consider an artist whose personal experiences have been quite trying, and who accordingly deals mainly in negative emotions such as distress, isolation, and self-loathing. Such a person might have intense feelings of personal expressiveness while working on art objects that express or portray these emotions. A person who fits this profile might even be doing as well as they possibly could be, given their temperament and situation, if there were no other candidate values that attracted or excited them. However, the theory defended here plausibly implies that the person could not be doing especially well: their feelings of personal expressiveness are tied to negative, burdensome emotions that do not (other things being equal) dispose them to realize their values.

\subsection{Defending Eudaimonic Models Against their Critics}

Eudaimonic models of well-being and happiness have been criticized, first, on the grounds that the study of eudaimonia, as opposed to SWB, is "poorly unified" (Biswas-Diener et al. 2009 , p. 209), and second, on the grounds that "the search for something 'better' than SWB ... connotes a potential elitism" and therefore imposes a vision of the Good Life on individuals (Kashdan et al. 2008, p. 227). A related criticism is that eudaimonic models are not adequately flexible to explain welfare and happiness in non-Western or collectivist cultures (cf. Della Fave et al. 2011a). Well-being as agential flourishing is well-placed to defuse these objections while still incorporating numerous valuable insights from the leading eudaimonic models.

When looked at individually, eudaimonic models may appear to be diverse and irregular. But well-being as agential flourishing exposes and stays true to their common core: these models focus on activities that are governed by integrated or self-realization values, as well as the cultivation of the capacities and abilities that are needed for these to be successful over a lifetime. Features idiosyncratic to particular eudaimonic models-the postulation of innate and universal human trajectories, dimensions of social functioning, feelings (as opposed to beliefs) of personal expressiveness, the postulation of a nascent true self-should not distract us from this common core.

The present model avoids the elitism charge by focusing on the agent's own values, as well as the states and capacities that underwrite the agent's disposition to succeed. Like eudaimonic models, the theory implies that mental health is a beneficial state whether one desires it or not. But this is still explained by reference to one's own values: it is a 
beneficial state because it is a general purpose facilitator of the achievement of values, whatever one's particular values happen to be. Even though the theory is individualistic in one sense, because it focuses on personal values, since these might include various traditional or collectivist values, it seems that it would also render credible verdicts about the welfare of individuals who hold such values.

Although this flexibility therefore has certain benefits, some might object to the theory on the grounds that it does not build into its conception of well-being a requirement for moral virtue. Some argue that the pursuit of immoral values is strictly incompatible with personal welfare (e.g., Ryan et al. 2008, p. 141).

In response, it should be noted that, since most people care directly about other people as well as moral ideals, the pursuit of moral and pro-social concerns is a very important source of well-being for most people (cf. Della Fave et al. 2011a). Furthermore, given the nature and acculturation of most actual human persons, moral and pro-social values are ideal candidates for lifetime values: they are likely to excite a person's interest, give them purpose in life, and afford opportunities for personal growth over the course of a whole life. (In this respect, they resemble the love of natural environments, appreciation of music, and the exercise of creativity.) Moral and pro-social values also complement the other values people are likely to have, when they are pursued. Furthermore, over time, the pursuit of moral and pro-social values strengthens one's disposition to realize one's own values, since it wins one the cooperation of others, which cooperation will be more forthcoming if one is courteous, kind, and fair-minded. Taken together, these points support the proposition that, in the context of a whole life, it is beneficial to hold and pursue moral and pro-social values.

Some, though, might wish to modify the theory so that one must be morally virtuous to a high degree or have pro-social goals and concerns in order to be fairing well. This would be to adopt a theory of well-being as morally virtuous, pro-social agential flourishing. But it is not clear that the theory ought to be developed in this way. It might be a mark in favor of the theory that it does not impose what Kashdan et al. call "an artificial moral hierarchy" on forms of welfare and happiness (cf. Williams 1985; Frankfurt 2002; Haybron 2008). The view that moral and pro-social concerns are mandatory from the point of view of wellbeing, even in the short-term, would yield counterintuitive implications about what would benefit and harm the minority of individuals who prefer solitude and solitary pursuits. It would make it impossible for a morally vicious or wicked person to prosper or flourish to a significant degree at a time, when it does seem possible for such people to fare well and to benefit from their own vice, at least in the short-term. Perhaps the form of criticism most appropriate to such individuals is not that, in virtue of their wickedness, they are faring badly. Perhaps the form of criticism most appropriate to such individuals is that their actions are morally wrong, because (e.g.) they treat others in thoughtless or abusive ways and thereby violate rules that ought to be part of our social code (Scanlon 1998; Watson 1998; Hooker 2002). Welfare-value, on this way of thinking, is but one form of ethical value, and a theory of personal welfare cannot serve as a comprehensive moral outlook or a theory of societal well-being. Similarly, moral motivation is not grounded in self-interest alone, but in direct concern for others and a desire to live in a way that is justifiable to others.

\section{Conclusion}

The predicate "is happy" and its cognates can be used to express both the concept of episodic happiness and the concept of happiness in the personal attribute sense. Ordinary 
English usage distinguishes between both of these forms of happiness, on the one hand, and well-being, on the other. Philosophical arguments verify that these forms of happiness are conceptually, metaphysically, and extensionally distinct from welfare: they are compatible with seriously impaired agency and dysfunctional emotional and motivational systems, while well-being is not.

A new theory of welfare, well-being as agential flourishing, proposes the following connections between happiness and well-being. First, both episodic happiness and happiness in the personal attribute sense can be, and frequently are, valued for their own sake. When people realize these values, that directly benefits them, provided that it does not detract from their agential flourishing by significantly undermining their disposition to realize their other main values. In most cases, the emotional states that constitute both forms of happiness actually serve to underwrite or constitute these dispositions. A minimal level of both forms of happiness makes it more likely that one will value things, that one will deliberate reliably about how to realize one's values, and that one will have the energy and perseverance to act on behalf of one's values. Furthermore, if a person experiences episodic happiness in the process of pursuing their values, or as a concomitant of successful activity, it is directly beneficial because it underwrites and strengthens their disposition to succeed. The emotional states that constitute episodic happiness are also partially constitutive of certain forms of valuing as an activity.

This theory also explains the disvalue of episodic unhappiness. Sufficiently intense negative affect disrupts one's ability to hold values and act on their behalf. Unhappiness in the personal attribute sense is also directly harmful: being harried, anxious, defensive, emotionally closed off, or hunkered down-i.e., compressed-is harmful precisely because it is disruptive of values-formation and goal-directed action, as well as other states like endorsement, attunement, and engagement, which dispose one to form and pursue values.

The agential flourishing theory overlaps in significant ways with leading accounts of welfare and happiness from the eudaimonic tradition in psychology. Like these theories, it emphasizes the importance for welfare of an active life centered on the realization of selfcongruent values, as well as the maintenance of the capacities and abilities that make this possible. Also like such theories, it assigns a supporting-but still important-role to hedonic enjoyment. The theory simultaneously addresses common objections to such models.

Acknowledgments I would like to thank Fred Feldman, Dan Haybron, Alan Waterman, the editor of this journal, and two anonymous referees for helpful feedback on the ideas in this paper.

\section{References}

Annas, J. (1993). The morality of happiness. New York: Oxford University Press.

Arneson, R. (1999). Human flourishing versus desire satisfaction. Social Philosophy and Policy, 16(1), $113-142$.

Bentham, J. (1907). Principles of morals and legislation. Oxford: Oxford University Press.

Binmore, K. (2009). Interpersonal comparisons of utility. In H. Kincaid \& D. Ross (Eds.), Oxford handbook of philosophy of economics (pp. 540-559). New York: Oxford University Press.

Biswas-Diener, R., Kashdan, T. B., \& King, L. A. (2009). Two traditions of happiness research, not two distinct types of happiness. Journal of Positive Psychology, 4(3), 208-211.

Bond, E. J. (1988). 'Good' and 'good for': A reply to Hurka. Mind, 97(386), 279-280.

Boyd, R. (1999). Homeostasis, species, and higher taxa. In R. A. Wilson (Ed.), Species: New interdisciplinary essays (pp. 141-185). Cambridge, Mass: MIT Press.

Bratman, M. (1996). Identification, decision, and treating as a reason. In M. Bratman (Ed.), Faces of intention (pp. 185-206). New York: Cambridge University Press. 
Brown, K. W., \& Ryan, R. M. (2003). The benefits of being present: Mindfulness and its role in psychological well-being. The Journal of Personality and Social Psychology, 84(4), 822-848.

Csíkszentmihályi, M. (1990). Flow: the psychology of optimal experience. New York: Harper and Row.

Darwall, S. (2002). Welfare and rational care. Princeton, NJ: Princeton University Press.

Davis, W. (1981). A theory of happiness. American Philosophical Quarterly, 18(2), 111-112.

Deci, E. L., \& Ryan, R. M. (2000). The 'what' and 'why' of goal pursuits: Human needs and the selfdetermination of behavior. Psychological Inquiry, 11(4), 227-268.

Della Fave, A., et al. (2011). The eudaimonic and hedonic components of happiness: Qualitative and quantitative findings. Social Indicators Research, 100, 185-207.

Della Fave, A. et al. (2011b). Hedonism and eudaimonism in positive psychology: Psychological selection and optimal experience across cultures. In A. Della Fave (Ed.), Cross-Cultural Advancements in Positive Psychology 2, 3-18.

Diener, E. (2000). Subjective well-being: The science of happiness and a proposal for a national index. American Psychologist, 55(1), 34-43.

Diener, E., \& Lucas, R. E. (1999). Personality and subjective well-being. In D. Kahneman, E. Diener, \& N. Schwarz (Eds.), Well-being: The foundations of hedonic psychology. New York: Russell Sage Foundation.

Dworkin, R. (1994). Life's dominion: An argument about abortion and euthanasia. New York: Vintage Books.

Easterlin, R. A. (2005). Building a better theory of well-being. In L. Bruni \& P. L. Porta (Eds.), Economics and happiness: Framing the analysis (pp. 29-64). New York: Oxford University Press.

Fara, M. (2006). Dispositions. The Stanford encyclopedia of philosophy. From http://plato.stanford. edu/entries/dispositions/. Accessed June 27, 2011.

Feldman, F. (2004). Pleasure and the good life. New York: Oxford University Press.

Feldman, F. (2010). What is this thing called happiness?. New York: Oxford University Press.

Frankfurt, H. (1998). Identification and wholeheartedness. In H. Frankfurt (Ed.), The importance of what we care about (pp. 159-176). New York: Cambridge University Press.

Frankfurt, H. (2002). Reply to Susan Wolf. In S. Buss \& L. Overton (Eds.), Contours of agency. Cambridge, Mass: MIT Press.

Frederickson, B., \& Losada, M. (2005). Positive affect and the complex dynamics of human flourishing. American Psychologist, 60(7), 67-86.

Gaus, G. (1990). Value and justification. New York: Cambridge University Press.

Haybron, D. M. (2008). The pursuit of unhappiness. New York: Oxford University Press.

Heathwood, C. (2006). Desire satisfactionism and hedonism. Philosophical Studies, 128, 547-551.

Heathwood, C. (2007). The reduction of sensory pleasure to desire. Philosophical Studies, 133, $23-44$.

Hooker, B. (2002). Ideal code, real world. New York: Oxford University Press.

Kahneman, D. (1999). Objective happiness. In D. Kahneman, E. Diener, \& N. Schwarz (Eds.), Well-being: The foundations of hedonic psychology (pp. 3-25). New York: Russell Sage Foundation.

Kahneman, D., Diener, E., \& Schwarz, N. (Eds.) (1999). Well-being: The foundations of hedonic psychology. New York: Russell Sage Foundation.

Kashdan, T. B., Biswas-Diener, R., \& King, L. A. (2008). Reconsidering happiness: The costs of distinguishing between hedonics and eudaimonia. Journal of Positive Psychology, 3, 219-233.

Katz, L. (2008). Pleasure. The Stanford encyclopedia of philosophy. From http://plato.stanford.edu/ archives/win2003/entries/pleasure/. Accessed June 27, 2011.

Keller, S. (2009). Welfare as Success. Nous, 43(44), 656-683.

Keyes, C. L. M. (2002). The mental health continuum: From languishing to flourishing in life. Journal of Health and Behavior Research, 43, 207-222.

Keyes, C. L. M. (2007). Promoting and protecting mental health as flourishing. American Psychologist, 62(2), 95-108.

Keyes, C. L. M., Shmotkin, D., \& Ryff, C. D. (2002). Optimizing well-being: The empirical encounter of two traditions. Journal of Personality and Social Psychology, 82(6), 1007-1022.

Kraut, R. (1979). Two conceptions of happiness. Philosophical Review, 88, 167-197.

Larsen, R. J., \& Diener, E. (1992). Promises and problems with the circumplex model of emotion. Review of Personality and Social Psychology, 13, 25-59.

Lukas, M. (2010, June). Desire satisfactionism and the problem of irrelevant desires. Journal of Ethics and Social Philosophy. From http://www.jesp.org/. Accessed June 27, 2011.

McMahon, J. (2002). The ethics of killing. New York: Oxford University Press.

Murphy, M. C. (1999). The simple desire-fulfillment theory. Nô̂s, 33(2), 247-272.

Norton, D. (1976). Personal destinies. Princeton, NJ: Princeton University Press.

Nussbaum, M. (2006). Frontiers of justice. Cambridge, Mass: Harvard University Press. 
Nussbaum, M. (2011). Creating capabilities. Cambridge, Mass: Belknap/Harvard University Press.

Prior, E., Pargetter, R., \& Jackson, F. (1982). Three theses about dispositions. American Philosophical Quarterly, 19, 251-257.

Putnam, H. (1975). The meaning of 'meaning'. In H. Putnam (Ed.), Mind, language, and reality. New York: Cambridge University Press.

Russell, J. A. (1980). A circumplex model of affect. Journal of Personality and Social Psychology, 39, $1161-1178$.

Ryan, R. M., \& Deci, E. L. (2001). On happiness and human potentials: A review of research on hedonic and eudaimonic well-being. Annual Review of Psychology, 52, 141-166.

Ryan, R. M., Huta, V., \& Deci, E. L. (2008). Living well: A self-determination theory perspective on eudaimonia. Journal of Happiness Studies, 9, 139-170.

Ryff, C. D., \& Keyes, C. L. M. (1995). The structure of psychological well-being revisited. Journal of Personality and Social Psychology, 69(4), 719-727.

Ryff, C. D., \& Singer, B. (1998). The contours of positive human health. Psychological Inquiry, 9(1), 1-28.

Scanlon, T. M. (1998). What we owe to each other. Cambridge, Mass: Belknap/Harvard University Press.

Seligman, M. E. P. (2011). Flourish: A visionary new understanding of happiness and well-being. New York: Free Press.

Sen, A. (1985). Well-being, agency, and freedom. Journal of Philosophy, 82, 169-221.

Sen, A. (1993). Capability and well-being. In A. Sen \& M. Nussbaum (Eds.), The quality of life. New York: Oxford University Press.

Sen, A. (2009). The idea of justice. Cambridge, Mass: Belknap/Harvard University Press.

Sheldon, K. M. (2004). Optimal human being: An integrated multi-level perspective. Hillsdale, NJ: Erlbaum.

Sumner, L. W. (1996). Welfare, happiness, and ethics. New York: Oxford University Press.

Tiberius, V. (2008). The reflective life. New York: Oxford University Press.

Tiberius, V., \& Hall, A. (2010). Normative theory and psychological research: Hedonism, eudaimonism, and why it matters. Journal of Positive Psychology, 5(3), 212-225.

Von Neumann, J., \& Morgenstern, O. (1944). The theory of games and economic behavior. Princeton, NJ: Princeton University Press.

Waterman, A. (1990). The relevance of Aristotle's conception of eudaimonia for the psychological study of happiness. Theoretical and Philosophical Psychology, 10(1), 39-43.

Waterman, A. (1993). Two conceptions of happiness: Contrasts of personal expressiveness and hedonic enjoyment. Journal of Personality and Social Psychology, 64(4), 678-691.

Waterman, A. (2008). The implications of two conceptions of happiness for the understanding of intrinsic motivation. Journal of Happiness Studies, 9, 41-79.

Watson, G. (1998). Some considerations in favor of contractualism. In C. Morris \& J. Coleman (Eds.), Rational commitment and morality. New York: Cambridge University Press.

Williams, B. (1985). Ethics and the limits of philosophy. Cambridge, Mass: Harvard University Press.

Wittgenstein, L. (1958). Philosophical investigations, 4th edn (P. M. S. Hacker \& J. Schulte, Trans.). Oxford: Wiley-Blackwell.

Zimmerman, M. J. (2010). Review of what is this thing called happiness? Resource document. Notre Dame Philosophical Reviews. From http://ndpr.nd.edu/review.cfm?id=20367. Accessed June 27, 2011. 